\title{
UNDILUTED IRON SUCROSE ADMINISTRATION IN PREGNANT WOMEN WITH IRON DEFICIENCY ANAEMIA
}

\author{
Anitha Thamarai Selvi Arumugam Nainar', Malarvizhi Loganathan² \\ ${ }^{1}$ Senior Assistant Professor, Department of Obstetrics and Gynaecology, Government Dharmapuri Medical College and Hospital, \\ Dharmapuri. \\ ${ }^{2}$ Associate Professor, Department of Obstetrics and Gynaecology, Government Dharmapuri Medical College and Hospital, Dharmapuri.
}

ABSTRACT

\section{BACKGROUND}

Iron deficiency anaemia is an important cause of maternal death in India. Iron folate tablet supplementation has been in India for more than 30 years, but without much success. IV iron sucrose has been a great boon to Indian women who refuse to take tablets for various reasons. Iron sucrose is usually given $200 \mathrm{mg}$ diluted with $100 \mathrm{~mL}$ NS over 10 to 15 minutes. When reconstituted iron sucrose breaks down over time forming free radicals, it causes various allergic reactions. In a poor resource setup, this could be costly. For the past 3 years in the Government Dharmapuri Medical College Hospital, we practised giving iron sucrose injection only as a bolus dose. For the purpose of this study, records of 500 patients were analysed for the effectiveness of the method.

\section{MATERIALS AND METHODS}

The study included 500 women from antenatal, postnatal, and post-LSCS ward with haemoglobin $<7$ g diagnosed to have iron deficiency anaemia. $200 \mathrm{mg}$ of iron sucrose was given in a single day. Every alternate day $200 \mathrm{mg}$ of the drug is given for a maximum of 3 doses or $600 \mathrm{mg}$ over a week. Patients were discharged after completing the dose with the advice to come for $\mathrm{Hb}$ measurement after 3 weeks or a month. Patient was observed for 30 minutes following the IV injection. Complaints like dizziness, palpitation, sweating, rashes, chest pain, joint or back pain were looked for and recorded. All patients with complaints were monitored with pulse oximeter for 30 minutes and ECG was taken for them.

\section{RESULTS}

None of the patients developed any major or life threatening reactions. Only a few patients developed minor reactions which got settled with CPM and reassurance.

\section{CONCLUSION}

IV bolus injection is cheaper and consumes less time than IV infusion and can be used as an alternative without fear of severe allergic reactions.

\section{KEYWORDS}

Iron Deficiency Anaemia (IDA), Iron-Folic Acid (IFA), Haemoglobin (Hb), IV Iron Sucrose, Bolus Injection.

HOW TO CITE THIS ARTICLE: Nainar ATSA, Loganathan M. Undiluted iron sucrose administration in pregnant women with iron deficiency anaemia. J. Evolution Med. Dent. Sci. 2017;6(20):1623-1626, DOI: 10.14260/Jemds/2017/355

\begin{abstract}
BACKGROUND
Nearly 40 years after the initiation of the iron-folic acid (IFA) program to provide free iron/folic acid supplementation to all pregnant women starting from the second trimester till 3 months of lactation, studies show that the prevalence of iron deficiency anaemia (IDA) during pregnancy in India is increasing and ranges between $50 \%$ and $60 \% .{ }^{1.2}$ Thus, the IFA program has failed to meet its primary objectives.

The reasons include partial coverage of the population, inadequate dosing of the iron supplement, short supplies, defective absorption due to intestinal infestations, diets containing high levels of iron chelators, problems with formulation, inadequate consumption or poor compliance by the beneficiaries, failure to replenish the stocks at the beneficiary level, and lack of effective health education and supervision. ${ }^{3}$
\end{abstract}

Financial or Other, Competing Interest: None.

Submission 01-02-2017, Peer Review 26-02-2017,

Acceptance 03-03-2017, Published 09-03-2017.

Corresponding Author:

Dr. Anitha Thamarai Selvi Arumugam Nainar,

\#4/637 B, Kadalai Mandi Street,

Teachers Colony, Dharmapuri-636701.

E-mail: anithathamaraiselvi@gmail.com

DOI: $10.14260 /$ jemds $/ 2017 / 355$
In the developed countries, it has been found that intravenous (IV) iron supplementation is effective in the treatment of IDA 4.5 in various conditions, including pregnancy. There are evidences that compared to oral iron, IV iron sucrose results in a much more rapid resolution of IDA, has minimal side effects, and circumvents many of the problems associated with the IFA Program such as noncompliance.

Unlike intravenous dextran iron, anaphylactic reactions are very rare with iron sucrose. According to conventional practice, iron sucrose should be administered by a slow intravenous infusion at doses of 50 to $100 \mathrm{mg}$ at one sitting. As majority of Indian women get affected by mild-tomoderate anaemia during pregnancy, they would require multiple infusions to make up for the total dose calculated by the standard formula [2.4 $\mathrm{x}$ weight in $\mathrm{kg}$ (target $\mathrm{Hb}$-actual $\mathrm{Hb})$ ] and each such infusion increases the cost of treatment significantly.

It has been observed that despite educational campaigns and other measures to encourage the uptake of treatments, there is poor response in cases when a treatment requires several hospital visits. Therefore, the challenge is to develop and/or evaluate treatment regimens that are efficacious, safe, and cost effective and minimise hospital visits. 
An observational study was conducted to study the safety and cost of providing intravenous iron sucrose via a bolus push technique over 2 to 5 minutes rather than the conventional slow intravenous infusion used everywhere. A maximal permissible dose of $200 \mathrm{mg}$ of IV iron sucrose was administered at one sitting, instead of 50 to $100 \mathrm{mg}$ per dose in order to minimise the number of visits and maximise compliance.

\section{MATERIALS AND METHODS}

\section{Sample Size}

500 patients were studied over a period of 3 months. 50 patients were in antenatal ward in the $2^{\text {nd }}$ trimester. 250 in the post-natal ward \& 200 in the post LSCS ward. (Table 1, 2, 3).

\section{Study Design/Observational Study Inclusion Criteria}

Pregnant women with anaemia $(\mathrm{Hb}<11$ g/dL) and gestational age of 20 to 24 weeks, women status post delivery in postnatal and postoperative ward were included in the study conducted between May 2016 and August 2016 at Govt. Dharmapuri Medical College Hospital, Dharmapuri.

\section{Exclusion Criteria}

Women who were taking oral iron supplement, who received a blood transfusion within a year, and those previously investigated and confirmed to be carriers of either thalassaemia or sickle cell gene were excluded from the study.

Written informed consent was obtained from all participants.

Proportion of Women getting the Target Haemoglobin Level

Demographic Profile

\begin{tabular}{|c|c|c|c|c|}
\hline Antenatal & Total & $\begin{array}{c}\mathbf{H b} \\
\mathbf{< 7} \mathbf{g}\end{array}$ & $\begin{array}{c}\mathbf{H b} \\
\mathbf{7 - 7 . 9} \mathbf{g}\end{array}$ & $\begin{array}{c}\mathbf{H b} \\
\mathbf{8 - 8 . 9} \mathbf{g}\end{array}$ \\
\hline I Trimester & 30 & 30 & - & - \\
\hline II Trimester & 12 & - & 10 & 2 \\
\hline III Trimester & 8 & - & - & 8 \\
\hline \multicolumn{5}{|c|}{ Table 1 } \\
\hline
\end{tabular}

\begin{tabular}{|c|c|c|c|}
\hline & Hb $<7$ g & Hb 7-7.9 g & Hb 8-8.9 g \\
\hline Antenatal & 5 & 23 & 22 \\
\hline Post-natal & 8 & 148 & 44 \\
\hline Post LSCS & 12 & 172 & 66 \\
\hline \multicolumn{4}{|c|}{ Table 2 } \\
\hline
\end{tabular}

\begin{tabular}{|c|c|c|c|}
\hline Parameter & $\begin{array}{c}\text { Hb } \\
<\mathbf{7} \mathbf{g}\end{array}$ & $\begin{array}{c}\text { Hb } \\
\mathbf{7 - 7 . 9} \mathbf{g}\end{array}$ & $\begin{array}{c}\text { Hb } \\
\mathbf{8 - 8 . 9} \mathbf{g}\end{array}$ \\
\hline Age & & & 1 \\
\hline$<20$ Yrs. & 6 & 4 & 129 \\
\hline $20-30$ Yrs. & 14 & 336 & 2 \\
\hline$>30$ Yrs. & 5 & 3 & Hb 8-8.9 g \\
\hline Parity & Hb $<7 \mathbf{g}$ & Hb 7-7.9 g & 0 \\
\hline Nulli & 0 & 0 & 84 \\
\hline Primi & 11 & 45 & 48 \\
\hline Multi & 14 & 298 & \\
\hline \multicolumn{4}{|c|}{ Table 3 } \\
\hline
\end{tabular}

\section{Materials and Methods}

One tablet of albendazole was administered to all women for deworming before starting the treatment. Hb estimation was performed using Sahli's method. ${ }^{6.7}$ Iron sucrose is available as $100 \mathrm{~mL}$ ampoules in TN Government supply, 2 ampoules of the drug is loaded in $10 \mathrm{~mL}$ syringe and given in a fresh IV line, a scalp vein set or Venflon is fixed or directly given with needle. When given in an old Venflon, a few drops of DW/NS is pushed before giving the drug.

Details about the patients including the previous treatment for anaemia; any allergic history are recorded. Patient was observed for 30 minutes following the IV injection. Complaints like dizziness, palpitation, sweating, rashes, chest pain, joint or back pain were looked for. Emergency drugs to manage anaphylactic reaction were kept ready. All patients with complaints were monitored with pulse oximeter for 30 minutes and ECG was taken.

None of the patients developed any major or life threatening reactions. 77 patients complained of palpitation and chest discomfort but on examination their PR and vitals were normal and were managed with just reassurance. 23 patients had sweating with mild tachycardia which got settled and reassurance. 8 patients complained of severe back pain which was managed with IM Diclofenac. [Even when the patient had reaction during previous iron sucrose injection in PHC given as infusion, IV bolus injections were given to them without any reactions]. In no patients drug dosage was stopped because of reaction.

Every alternate day $200 \mathrm{mg}$ of the drug is given for a maximum of 3 doses or $600 \mathrm{mg}$ over a week. For Hb less than $7 \mathrm{~g}$ [after blood transfusion], 3 doses or $600 \mathrm{mg}$; for $\mathrm{Hb} 7$ to 7.9, 2 doses or $400 \mathrm{mg}$; for $\mathrm{Hb} 8$ to 8.9, 1 dose of $200 \mathrm{mg}$ Patient is discharged after completing the dose with the advice to take iron rich diet and $\mathrm{Hb}$ measurement after 3 weeks or a month.

\section{RESULTS}

\section{Adverse Reactions-}

Of the 500 patients taken for study, 107 (21.4\%) developed mild symptoms without any recordable signs managed with reassurance only.

$23(4.6 \%)$ developed signs and symptoms requiring simple drug treatment.

$1(0.2 \%)$ patient developed severe fasciitis requiring fasciotomy due to extravasation of the drug. (Table 4).

\begin{tabular}{|c|c|c|c|c|}
\hline Side Effects & Antenatal & $\begin{array}{c}\text { Post } \\
\text { Natal }\end{array}$ & $\begin{array}{l}\text { Post } \\
\text { LSCS } \\
\end{array}$ & Total \\
\hline Chest pain & 3 & 18 & 22 & 43 \\
\hline Breathing difficulty & 4 & 12 & 12 & 28 \\
\hline Sweating & 0 & 11 & 12 & 23 \\
\hline Pain at injection site & 0 & 4 & 10 & 14 \\
\hline Giddiness & 2 & 3 & 3 & 8 \\
\hline Joint/Back Pain & 0 & 8 & 0 & 8 \\
\hline Palpitation & 0 & 2 & 4 & 6 \\
\hline Fasciitis & 0 & 0 & 1 & 1 \\
\hline Rashes* & 0 & 0 & 0 & 0 \\
\hline Metallic taste* & 0 & 0 & 0 & 0 \\
\hline Fever* & 0 & 0 & 0 & 0 \\
\hline Nausea/Vomiting* & 0 & 0 & 0 & 0 \\
\hline $\begin{array}{c}\text { Diarrhoea/ } \\
\text { Constipation* }\end{array}$ & 0 & 0 & 0 & 0 \\
\hline TOTAL & $\begin{array}{l}9(50) \\
=18 \%\end{array}$ & $\begin{array}{c}58 \\
(200) \\
=28 \%\end{array}$ & $\begin{array}{c}64 \\
(250) \\
24.8 \%\end{array}$ & $\begin{array}{c}131 \\
(500) \\
26.2 \%\end{array}$ \\
\hline \multicolumn{5}{|c|}{ Table 4. Side Effects } \\
\hline
\end{tabular}


*none of the patient had these complications which are common with iron dextran and oral iron.

\section{Time Effectiveness}

Bolus injection is both cost effective and time effective compared to IV infusion. It takes 30 minutes to administer and 30 minutes to observe the patient in infusion. In 30 minutes IV bolus can be administered to 5 patients. This is significant in rural areas like ours where the number of anaemia cases are more.

\section{Cost Effectiveness}

IV infusion needs IV set, $100 \mathrm{~mL}$ normal saline, which when not available $500 \mathrm{~mL}$ NS was used after discarding $400 \mathrm{~mL}$, in a government hospital setup. Some amount of drug gets wasted in the IV set and the saline bottle. IV bolus is much cheaper than infusion.

\section{Change in Severity of Anaemia in Response to Intravenous Iron Sucrose}

Change in severity of anaemia in response to intravenous iron sucrose was assessed in women who received iron sucrose. $\mathrm{Hb}$ estimation at 4 weeks was done. Of the 500 women studied, 325 (65\%) came for followup after 4 weeks and their $\mathrm{Hb}$ level significantly improved and were followed up with oral iron (Table 5, 6).

\section{Followup of Cases}

\begin{tabular}{|c|c|c|c|}
\hline Followup & $\begin{array}{c}\text { Total } \\
\text { Cases }\end{array}$ & $\begin{array}{c}\text { Came for } \\
\text { Followup }\end{array}$ & $\begin{array}{c}\text { No } \\
\text { Followup }\end{array}$ \\
\hline Antenatal & 50 & 47 & 3 \\
\hline Post Natal & 200 & 102 & 98 \\
\hline $\begin{array}{c}\text { Post- } \\
\text { Operative }\end{array}$ & 250 & 176 & 74 \\
\hline Total & $\mathbf{5 0 0}$ & $\mathbf{3 2 5}(\mathbf{6 5 \% )}$ & $\mathbf{1 5 0}$ (35\%) \\
\hline \multicolumn{4}{|c|}{ Table 5 } \\
\hline
\end{tabular}

\begin{tabular}{|c|c|c|c|c|c|}
\hline & $\begin{array}{c}\text { Cases } \\
\text { Followed } \\
\text { Up }\end{array}$ & \multicolumn{4}{|c|}{$\begin{array}{c}\text { Post-Treatment } \\
\text { Hb Value }\end{array}$} \\
\hline & & $9-10$ & $8-9 \mathrm{~g}$ & $\begin{array}{c}7-8 \\
\mathrm{~g}\end{array}$ & $\begin{array}{c}<7 \\
\mathrm{~g}\end{array}$ \\
\hline Antenatal & $47(94 \%)$ & 38 & 4 & 3 & $2^{*}$ \\
\hline Postnatal & $102(51 \%)$ & 81 & 18 & 2 & $1^{*}$ \\
\hline Post-Operative & $176(70 \%)$ & 172 & 2 & 2 & - \\
\hline Total & $\mathbf{3 2 5}(\mathbf{6 5 \% )}$ & $\mathbf{2 9 1}$ & $\mathbf{2 4}$ & $\mathbf{7}$ & $\mathbf{3}^{*}$ \\
\hline Table 6. Haemoglobin Level after Treatment \\
\hline
\end{tabular}

\section{DISCUSSION}

The case for establishing supplementation programs that can effectively eradicate IDA during pregnancy in developing countries cannot be overstated. In India, where maternal mortality is as high as 350 to 450 per 100,000 live births (a figure similar to that found in Europe 200 years ago), anaemia is estimated to lead to $20 \%$ of all maternal deaths. ${ }^{8}$

The often unrecognised consequence of maternal IDA is the impact on the foetus, newborn, child, and subsequent adult. Anaemia and iron deficiency during pregnancy are associated with large placental weight and a high placental ratio (Ratio of placental weight to birth weight), both of which are predictors of adult hypertension. 9,10
In newborns, IDA is associated with poor performance in the Bayley Mental Development Index. ${ }^{11}$ Although nutritional factors may be contributory, it is likely that IDA during infancy and early childhood is largely secondary to maternal iron deficiency during pregnancy. The definitive solution is to eradicate iron deficiency during or before pregnancy. The increasing prevalence of IDA during pregnancy nearly 40 years after the initiation of IFA program is an indication of the failure of this program and the urgent need to explore alternative approaches. Data from this study corroborated previous reports from developed countries on the safety and efficacy of intravenous iron sucrose during pregnancy. ${ }^{12}$

Challenges posed by attempts to use iron sucrose as a tool for the mass eradication of IDA in developing/underdeveloped areas include the cost of drug and method of its administration, logistics of administering several infusions of the drug to women who need it most, compromising compliance, and potential concerns about adverse reactions and how they might be handled in such settings.

In the present study, authors sought to evaluate ways in which these impediments might be overcome. If iron sucrose could be used on a mass scale, this would eventually drive down the cost of drug, especially if generic formulations could be developed. This is a challenge for the government and pharmaceutical industry. The use of bolus push technique has a potential for cost savings because it does not require hospital bed and other paraphernalia associated with the conventional infusion technique of iron sucrose administration.

This study showed that bolus push technique is indeed a feasible approach with similar efficacy to the conventional technique, and corroborated the previous report by MacDougall et al ${ }^{13}$ who demonstrated the safety of $200 \mathrm{mg}$ iron sucrose administered as a 2-minute bolus push in a total of 2297 injections. It was observed that, as in this study, a higher incidence of adverse reactions with bolus push technique was reported, but all the adverse reactions were minor in nature.

From the cost aspect, the current finding that the bolus push technique is seven times cheaper than the conventional slow intravenous infusion increases the possibility that its use could render iron sucrose affordable for use on a mass scale as indicated by the experience of its use in patients on haemodialysis in India. ${ }^{14}$

At present, $200 \mathrm{mg}$ is the maximum IV iron sucrose dose considered safe for administration at one sitting. Current practice is that the required iron dose is calculated for each woman based on her $\mathrm{Hb}$ deficit and prepregnancy weight. In a rural setting, if the mean $\mathrm{Hb}$ level for most of the women in the initial stages of pregnancy is $9.0 \mathrm{~g} / \mathrm{dL}$ and their mean weight of is $46.0 \mathrm{~kg}$, calculations indicate that a single dose of $200 \mathrm{mg}$ iron sucrose would increase the $\mathrm{Hb}$ level to $>11 \mathrm{~g} / \mathrm{dL}$.

It is generally stated that in pregnancy an additional 500 mg iron is required to replenish stores. ${ }^{15}$ Researchers in this study gave an additional $200 \mathrm{mg}$ of iron sucrose, although this would be insufficient to replenish the stores. By doing so, they treated anaemia in women, leaving some spare albeit inadequate amount of iron for stores in those women who came back for the second dose of $200 \mathrm{mg}$. Also, this approach indicated the need for future evaluation of a single bolus dose. 
If the 400-mg dose (or higher) could be safely administered in a single bolus push, the woman would not need to return for several infusions, compliance no longer becomes an issue, and efficacy would be virtually guaranteed, and costs are substantially reduced. With regard to failure to exclude other causes of anaemia, from a pragmatic point of view, it is known that in rural settings such investigations are rarely conducted, whereas the most common cause of anaemia in such settings is known to be iron deficiency.

The authors aimed to evaluate a treatment regimen in a manner that would reflect how such treatment might be administered on a mass scale. The WHO/Indian Council of Medical Research criteria, which are based on $\mathrm{Hb}$ and do not include serum ferritin, were used to define iron deficiency anaemia in the present study. Unpublished data showed improved ferritin estimates after intravenous iron sucrose in an urban population. Therefore, the authors were confident that the increase in $\mathrm{Hb}$ would also be reflected in appropriate increases in serum ferritin.

The rate of loss to followup was very high in the present study (only 65\% turned up for followup). However, there was no correlation between the incidence of adverse reactions and rate of loss to followup. Therefore, it can be concluded that this high loss rate reflects what really does happen in practice - there is a high failure to complete treatment courses or comply with treatment.

This has major implications for any program designed to use IV iron sucrose to eradicate IDA in pregnancy, because women who need the treatment most $(\mathrm{Hb}<9 \mathrm{~g} / \mathrm{dL})$ are the ones who would need several visits if the iron sucrose were to be administered by several divided doses as per current convention. It is believed that a key potential solution might be to evaluate the use of a single dose of IV iron sucrose administered by the bolus push technique.

\section{CONCLUSION}

The bolus push technique for administration of intravenous iron sucrose may represent a cost-effective approach to the eradication of iron deficiency anaemia during pregnancy in low resource settings without the fear of life threatening reactions. Further studies are required on optimal iron sucrose dose regimens that could be administered as single total dose infusions.

\section{REFERENCES}

[1] Agarwal KN, Agarwal DK, Sharma A, et al. Prevalence of anemia in pregnant and lactating women in India. Indian J Med Res 2006;124(2):173-84.

[2] National Family Health Survey (NFHS-3) 2005-06. Vol. I. Mumbai, India. International Institute for Population Sciences 2007:191-222.
[3] Vijayaraghavan $\mathrm{K}$, Brahmam GN, Nair KM, et al. Evaluation of national nutritional anemia prophylaxis programme. Indian J Pediatr 1990;57(2):183-90.

[4] Bayoumeu F, Subiran-Buisset C, Baka NE, et al. Iron therapy in iron deficiency anemia in pregnancy: intravenous route versus oral route. Am J Obstet Gynecol 2002;186(3):518-22.

[5] al-Momen AK, al-Meshari A, al-Nuaim L, et al. Intravenous iron sucrose complex in the treatment of iron deficiency anemia during pregnancy. Eur J Obstet Gynecol Reprod Biol 1996;69(2):121-4.

[6] Anemia detection in health services: Guidelines for program managers. Washington, US: Program for Appropriate Technology in Health (PATH), 1996:37.

[7] Sood R. Concise book of medical laboratory technology methods and interpretations. Jaypee Brothers Medical 2006.

[8] Kodkany BS, Derman RJ, Goudar SS, et al. Initiating a novel therapy in preventing postpartum hemorrhage in rural India: a joint collaboration between the United States \& India. Int J Fertil Womens Med 2004;49(2):91-6.

[9] Godfrey KM, Redman CW, Barker DJ, et al. The effect of maternal anemia and iron deficiency on the ratio of fetal weight to placental weight. Br J Obstet Gynaecol 1991;98(9):886-91.

[10] Barker DJ, Bull AR, Osmond C, et al. Fetal and placental size and risk of hypertension in adult life. Br Med J 1990;301(6746):259-62.

[11] Oski FA. Iron deficiency-facts and fallacies. Paediatr Clin North Am 1985;32(2):493-7.

[12] Breymann C, Visca E, Huch R, et al. Efficacy and safety of intravenously administered iron sucrose with and without adjuvant recombinant human erythropoietin for the treatment of resistant iron-deficiency anemia during pregnancy. Am J Obstet Gynecol 2001;184(4):662-7.

[13] Macdougall IC, Roche A. Administration of intravenous iron sucrose as a 2-minute push to CKD women: a prospective evaluation of 2,297 injections. Am J Kidney Dis 2005;46(2):283-9.

[14] Jayaseelan T. Cost comparison, efficacy and safety of intravenous iron infusion versus push in maintenance haemodialysis patients in a tertiary care centre. Indian J Nephrol 2005;15:232-4.

[15] DeMaeyer E, Adiels-Tegman M. The prevalence of anaemia in the world. World Health Stat Q 1985;38(3):302-16. 